\title{
A review on nanosystems as an effective approach against infections of Staphylococcus aureus
}

This article was published in the following Dove Press journal:

International Journal of Nanomedicine

\author{
Kaixiang Zhou' \\ Chao $\mathrm{Li}^{\prime}$ \\ Dongmei Chen ${ }^{2}$ \\ Yuanhu Pan' \\ Yanfei Tao ${ }^{2}$ \\ Wei $\mathrm{Qu}^{2}$ \\ Zhenli Liu ${ }^{2}$ \\ Xiaofang Wang ${ }^{3}$ \\ Shuyu Xie'
}

'MOA Laboratory for Risk Assessment of Quality and Safety of Livestock and Poultry Products, Huazhong Agricultural University, Wuhan, Hubei, China; ${ }^{2}$ National Reference Laboratory of Veterinary Drug Residues (HZAU) and MAO Key Laboratory for Detection of Veterinary Drug Residues, Wuhan, Hubei, China; ${ }^{3}$ Animal Husbandry and Veterinary Institute of Hebei Province, Baoding, Hebei, China

Correspondence: Shuyu Xie MOA Laboratory for Risk Assessment of Quality and Safety of Livestock and Poultry Products, Huazhong Agricultural University, No I Shizishan Street,

Wuhan, Hubei 430070, China

Tel +86 2787287323 ext 822 I

Fax +86278767 2232

Email snxsyl@I26.com

Xiaofang Wang

Animal Husbandry and Veterinary

Institute of Hebei Province, Dongguan

Street 428, Baoding, Hebei 071000, China

Tel +86 I5 23/2 3/354

Email wangxiao.fang99@163.com

\begin{abstract}
Staphylococcus aureus (S. aureus) is an important zoonotic bacteria and hazardous for the health of human beings and livestock globally. The characteristics like biofilm forming, facultative intracellular survival, and growing resistance of $S$. aureus pose a great challenge to its use in therapy. Nanoparticles are considered as a promising way to overcome the infections' therapeutic problems caused by $S$. aureus. In this paper, the present progress and challenges of nanoparticles in the treatment of $S$. aureus infection are focused on stepwise. First, the survival and infection mechanism of $S$. aureus are analyzed. Second, the treatment challenges posed by $S$. aureus are provided, which is followed by the third step including the advantages of nanoparticles in improving the penetration and accumulation ability of their payload antibiotics into cell, inhibiting $S$. aureus biofilm formation, and enhancing the antibacterial activity against resistant isolates. Finally, the challenges and future perspective of nanoparticles for S. aureus infection therapy are introduced. This review will help the readers to realize that the nanosystems can effectively fight against the $S$. aureus infection by inhibiting biofilm formation, enhancing intracellular delivery, and improving activity against methicillin-resistant $S$. aureus and small colony variant phenotypes as well as aim to help researchers looking for more efficient nanosystems to combat the $S$. aureus infections.
\end{abstract}

Keywords: Staphylococcus aureus, infection mechanism, resistance, antibiotics, nanoparticles

\section{Introduction}

The infections caused by Staphylococcus aureus (S. aureus) seriously threaten human health and cause huge economic losses in farm. It is calculated that $\sim 30 \%$ healthy people colonized by $S$. aureus do not exhibit any symptoms. ${ }^{1-4} S$. aureus can cause many diseases such as skin infections, abscesses, impetigo, necrotizing pneumonia, septicemia, catheter-induced endocarditis, atherosclerosis, and osteomyelitis. ${ }^{5-7}$ Especially, the opportunistic infections in hospitals are extremely serious. It is reported that around $20 \%$ of surgical-site infections are caused by $S$. aureus. ${ }^{8}$ The highly virulent methicillin-resistant $S$. aureus (MRSA) is a worrying public health threat in countries all across the world, and different popular strains have been isolated in communities and hospitals. ${ }^{5}$ It was reported that the treatment cost of MRSA infections is $\$ 3,700$ and more than those of methicillin-sensitive $S$. aureus infections. Moreover, the death rate is about threefold that of the latter. ${ }^{9,10}$

In the livestock breeding, the bovine mastitis caused by $S$. aureus has induced a number of economic losses including the decrease of milk production and quality, increase of culling and death rates, and so on. ${ }^{11,12}$ Staphylococcal subclinical mastitis accounts for $30 \%$ bovine mastitis. ${ }^{13}$ It was reported that the $S$. aureus infections lead to a loss of about 380 tons of milk every year in the world. ${ }^{14}$ The presence of S. aureus in raw milk is also a public health problem throughout the food chain. The presence submit your manuscript

Dovepress

$f y$ in 6

http://dx.doi.org/10.2/47 
of $S$. aureus in cells can establish reservoirs from which reinfection will occur, ${ }^{15,16}$ and then result in long-term and repeated infection. ${ }^{17,18}$ The intracellular survival strategies of $S$. aureus are associated with the subclinical and relapsing infection of bovine mastitis.

The facultative intracellular parasitism and biofilm of $S$. aureus protect them from host immune responses and the effect of antibiotics, ${ }^{19}$ and thus present huge treatment challenges for the global medical community. In addition, the increasing resistance of $S$. aureus also leads to the treatment difficulty. Over decades, the nanoparticle carriers are reported to be one of the potential measures for improving their payload drug permeability across cell membrane, enhancing intracellular accumulation, increasing the antibacterial activity of antimicrobial agents against the resistant strains, offering multiple bactericidal mechanisms, and inhibiting the biofilm formation of S. aureus. We searched PubMed, Scopus, Web of Science, and Cochrane Central register of related publications about the application of nanoparticles in the treatment of intracellular infection using relevant keywords (nano, intracellular infections, intracellular delivery, S. aureus strategies, nanogel). About 3,625 records and 513 of closely related papers were screened for suitable studies. In this paper, the progress, challenges, and perspectives of nanomedicines for $S$. aureus infections are summarized according to the related publications to explore more efficient nanosystems to help human beings win the war against the $S$. aureus in the future.

\section{Invasion strategies of S. aureus}

$S$. aureus is a typical facultative intracellular bacterium. At the beginning of invasion, it first adheres to the surface of the body such as the skin and nasal cavity with the help of its secreted factors. ${ }^{20}$ The process of host adhesion is the key step for the pathogenesis of $S$. aureus. ${ }^{21,22} S$. aureus can secrete many kinds of factors (Table 1) to resist the immune response of hosts and thus achieve successful colonization. ${ }^{23,24}$ Among these, fibronectin-binding protein $\mathrm{A}$ (Fnbp A), Fnbp B, and wall teichoic acid promote the colonization. In these processes, S. aureus secretes some factors to assist in resistance to the host immune defenses. For example, iron-regulated surface determinant A (Isd A) can enhance bacterial cellular hydrophobicity and thus help $S$. aureus resist bactericidal fatty acids.

After host adhesion and colonization with the help of various factors, $S$. aureus invades cell and starts living within it. The bacteria can enter the cell and reside in special compartments using some smart mechanisms, leading to huge
Table I The function of various factors of Staphylococcus aureus

\begin{tabular}{l|l}
\hline Factors & Function \\
\hline SEA, SEB & Reduce the immune response of $\mathrm{TH}_{2}$ cytokines \\
\hline Fnbp A, Fnbp B & Bind with fibronectin, fibrinogen, and cytokeratins \\
\hline Aureolysin & Inhibits the antimicrobial activity of cathelicidin \\
\hline Isd A & $\begin{array}{l}\text { Enhances hydrophobicity; binds to fibrinogen; } \\
\text { relapsing reinfection }\end{array}$ \\
\hline Isd B & Binds with hemoglobin and hemin; relapsing reflection \\
\hline Isd C & Binds with hemin; relapsing reflection \\
\hline Isd H & $\begin{array}{l}\text { Binds to haptoglobulin and complex of haptoglobulin- } \\
\text { hemoglobin }\end{array}$ \\
\hline Sass, SassG & $\begin{array}{l}\text { Binds to extracellular matrix; involves in biofilm } \\
\text { formation }\end{array}$ \\
\hline Eap/Map & $\begin{array}{l}\text { Adhesion to host cell; damages angiogenesis and } \\
\text { wound healing }\end{array}$ \\
\hline
\end{tabular}

Abbreviations: Fnbp, fibronectin-binding protein; Isd, iron-regulated surface determinant.

difficulties for their cleaning by host immune system and antimicrobials. The survival and proliferation of $S$. aureus within cells were via preventing combination of phagosome and lysosome, subversion autophagy, and others. ${ }^{25}$ The toxin factors of $S$. aureus play a pivotal role (Table 2) in the process of penetration into cell membrane and intracellular survival. ${ }^{26}$ The $\beta$-toxin and $\delta$-toxin are reported to relate to the penetration across cell membrane. $\beta$-toxin can hydrolyze sphingomyelin, which constitutes the membrane into hydrophilic phosphorylcholine and hydrophobic ceramide. ${ }^{27}$ When the sphingomyelin is hydrolyzed by $\beta$-toxin, $\delta$-toxin accumulates in the hydrophobic ceramide domains and the bacteria eventually permeabilize the cytomembrane (Figure 1). ${ }^{28}$ It was reported that $\alpha$-toxin, a pore-forming toxin, can penetrate host cell membranes, and subsequently cause osmotic swelling, rupture, lysis, and cell death. ${ }^{29,30}$

After endocytosis, some bacteria can inhibit the fusion of phagosome and lysosome or escape from phagosome by certain factors and mechanisms (Figure 2). Grosz et al

Table 2 The functions of toxin factors of Staphylococcus aureus for intracellular survival

\begin{tabular}{l|l}
\hline $\begin{array}{l}\text { Toxin } \\
\text { factors }\end{array}$ & Function \\
\hline$\alpha$-toxin & Pore-forming toxin; lysis of cell membrane \\
\hline$\beta$-toxin & Hydrolyzes sphingomyelin \\
\hline$\delta$-toxin & Permeabilizes hydrophobic ceramide domains \\
\hline PSM $\alpha$ & Helps to escape from phagosomes or phagolysosome \\
\hline Leukocidins & Kills leukocytes; bicomponent pore-forming leukotoxins \\
$D, E$, and $M$ & \\
\hline
\end{tabular}

Abbreviation: PSM $\alpha$, phenol-soluble modulin $\alpha$. 

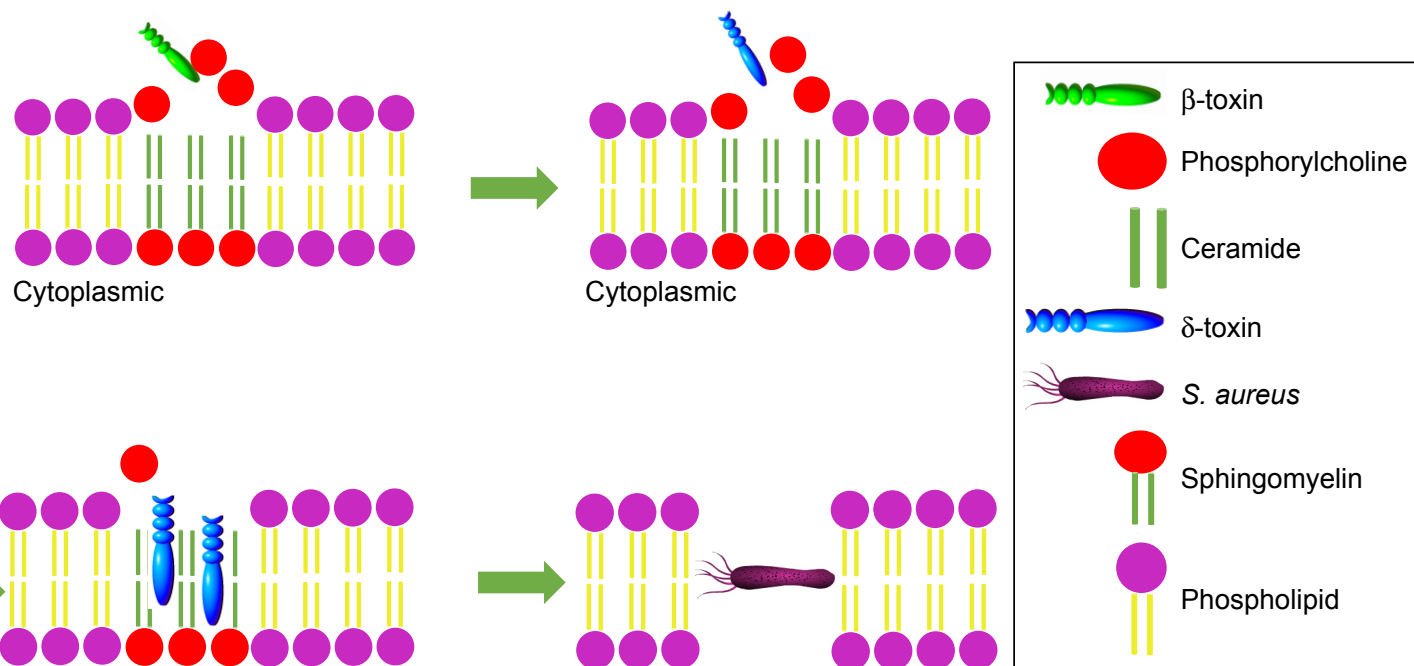

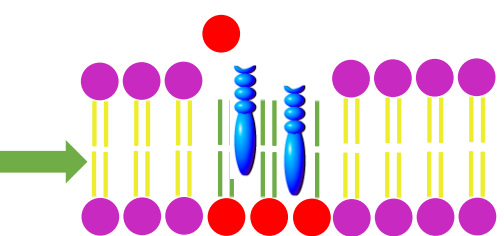

Cytoplasmic

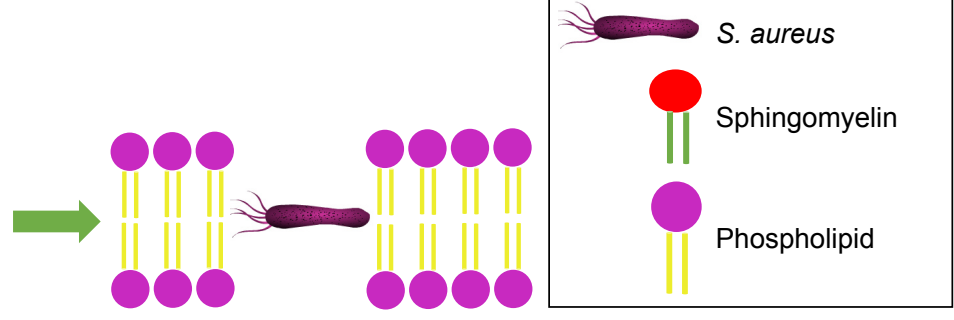

Cytoplasmic

Figure I The schematic diagram of Staphylococcus aureus permeabilization into cell membrane via $\beta$-toxin and $\delta$-toxin.

demonstrated that $S$. aureus 6850 , MW2, and LAC can escape from the phagosomes of phagocytes by mediation of phenol-soluble modulin $\alpha$ (PSM $\alpha){ }^{31}$ After cellular invasion, an intracellular niche served as a reservoir for the survival, and chronic carriage of $S$. aureus might be formed for the chronic and repeated infections. ${ }^{32}$

After successful infection, the small colony variants (SCVs) of S. aureus will be formulated..$^{33}$ There is a highly dynamic population between SCVs and normal phenotype.
Tuchscherr et al reported that $25 \%$ S. aureus will transform to SCVs without any selective pressure. ${ }^{35}$ Under the selective environmental stress, $S$. aureus will easily switch to SCVs. It can be induced by triclosan, cold stress, and high hydrostaticity. It is reported that the SCVs will arise when $S$. aureus is treated by antimicrobial agents in vitro culture. ${ }^{34}$ The SCVs are related to the resistance of $S$. aureus, reinfection, and chronic infections. ${ }^{36-38}$ The SCVs are difficult to be detected by host innate immune system via decreasing of

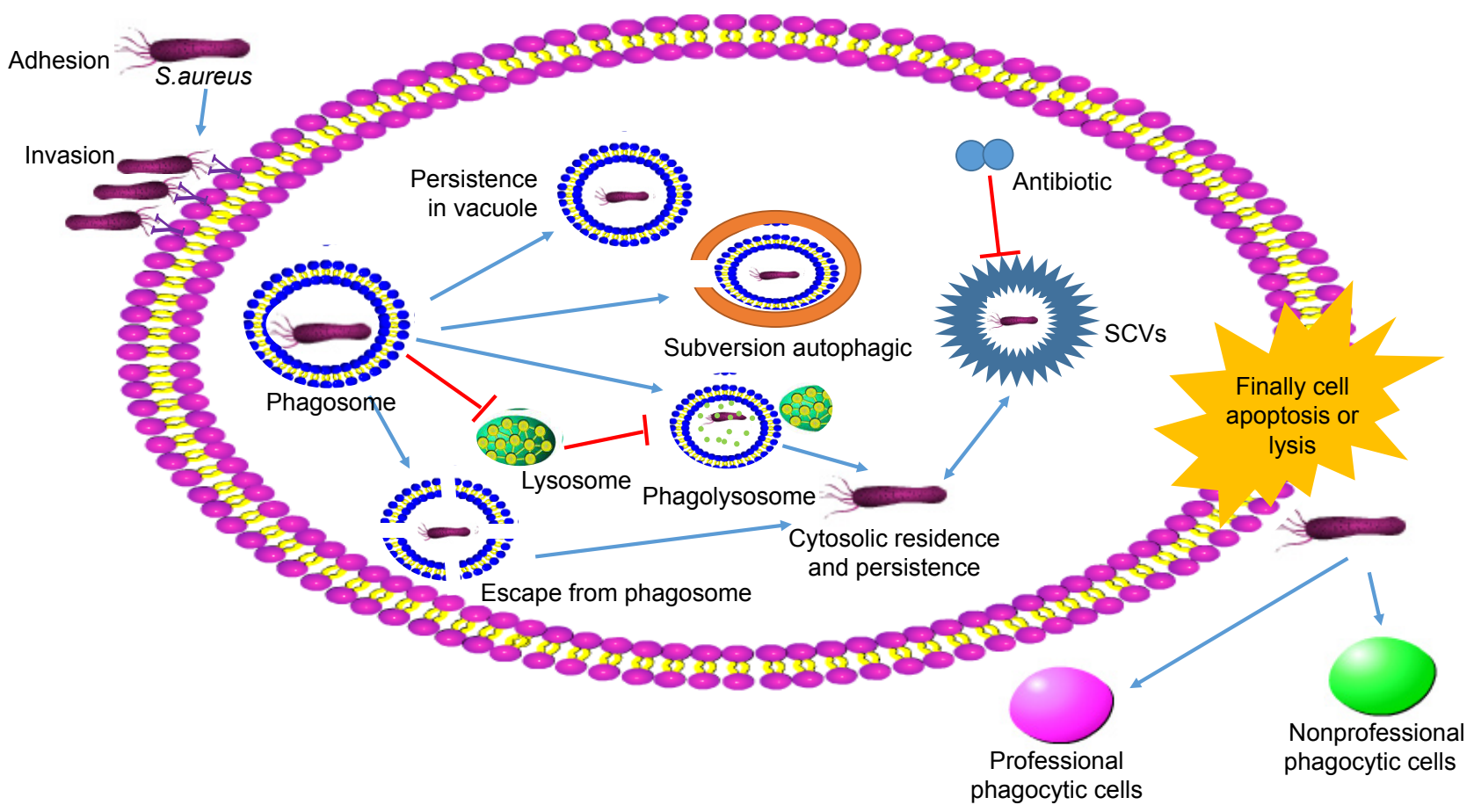

Figure 2 The mechanism of Staphylococcus aureus infection cells. Abbreviation: SCV, small colony variant. 
toxin and proinflammatory factor secretion when compared to normal phenotype.$^{39}$ It was reported that the intracellular infection of WCH-SK2 wild-type promoted the expression of much more factors (TLR2, tissue remodeling factors, and proinflammatory cytokines) than $\mathrm{WCH}-\mathrm{SK} 2^{\mathrm{SCV}}$ (only upregulated expression of TLR2). ${ }^{40}$ In addition, the metabolism level and growth of SCVs will be slower than the normal phenotype due to the obstacle of tricarboxylic acid metabolism and energy production, ${ }^{41-44}$ because of dependence to hemin, menadione and thymidine..$^{1,45}$

\section{Treatment challenges of S. aureus infections}

As mentioned earlier, $S$. aureus is able to escape the cleaning by the innate immune system and antimicrobial drugs with the help of various factors. The $\alpha$-toxin, $\beta$-toxin, $\delta$-toxin, PSM $\alpha$, and others contribute to multiplication and spread of the intracellular $S$. aureus and maintain their intracellular lifestyle. Some factors contribute to form a biofilm, which is propitious to escape the stress of antimicrobial agents and immunity. In addition, the SCV phenotype is one of the difficulties that we have met in the treatment of $S$. aureus infections due to their low metabolism level and the virulence factors are expressed less than normal phenotype. A large number of antibiotics are devoid of the ability of cell membrane and bacterial biofilm penetration, and intracellular short time retention, which results in inadequate intracellular distribution and low intracellular concentration. These make the $S$. aureus infection treatment highly challenging.

\section{S. aureus biofilms}

As we are well aware, the biofilm formation is a process of quorum sensing (QS). The small-molecule signals named autoinducers (AIs) will be secreted and will accumulate in the extracellular media when the bacteria multiply. When enough bacteria are reached, the AIs will enable single bacterium to sense other bacteria in their surroundings and could form biofilms. ${ }^{46}$ The formed biofilms exhibit higher virulence and resistance compared to planktonic $S$. aureus. Oyama et al reported that the thick biofilms of $S$. aureus showed higher virulence to mice livers than the thin biofilms. Moreover, the biofilms contribute to the intracellular survival of $S$. aureus and thus lead to chronic infections. ${ }^{47}$ It is well known that most drugs have poor permeability across the biofilms and exhibit poor activity against biofilm-forming $S$. aureus than that of planktonic S. aureus. Currently, $S$. aureus biofilms are a serious conundrum and no effective treatment methods are available so far.

\section{Intracellular survival}

One of the key challenges of intracellular S. aureus infections treatment is how to deliver enough antibacterial drugs to the site where intracellular bacteria are located. ${ }^{48}$ A multitude of antibiotics have low cell membrane penetration ( $\beta$-lactams and aminoglycosides), ${ }^{49}$ intracellular unabiding retention (fluoroquinolones and macrolides), inadequate intracellular distribution, and low intracellular concentration (Table 3). ${ }^{50,51}$ Therefore, intracellular $S$. aureus infection treatment is a great challenge for the global medical community. As mentioned earlier, S. aureus can easily switch to SCV phenotype and thus lower the metabolism level. Many antibiotics, especially the breeding-stage sterilization drugs (penicillin, cephalosporin), are invalid to them. As we know, membrane potential will be rapidly lowered when the flow of electrons in the electron transport chain is impaired. For aminoglycosides, its uptake by bacterial cells relies on the membrane potential. SCVs will occur when the electron transport chain breaks off, thereby reducing the membrane potential and hence limiting the uptake of aminoglycosides (eg, gentamicin). ${ }^{52}$ Moreover, the process of wild phenotype switching to SCV phenotype is often linked with the reduction of the number of ATP, ${ }^{53}$ which is necessary for drug molecules to enter into cytoplasm by active transport, macropinocytosis, or phagocytosis.

\section{Resistance}

The increasing resistance is another obstacle in the treatment of $S$. aureus infection. Their multidrug resistance gives them the ability to escape the pharmacologic action of antibiotics. During the earlier periods, what we knew more about the resistant strains of $S$. aureus was resistance to $\beta$-lactams, but recent reports have indicated that $S$. aureus has already been resistant to daptomycin ${ }^{54}$ and glycopeptide antibiotics (teicoplanin and vancomycin), which have been used to treat MRSA especially in severe infections. ${ }^{55}$

There are several main resistance mechanisms for $S$. aureus. The development of resistance genes is a key

Table 3 The challenges of conventional antimicrobial agents against Staphylococcus aureus infections

\begin{tabular}{l|l}
\hline Antibiotic & Challenge \\
\hline$\beta$-lactams & Poor permeability, causing resistance \\
\hline Aminoglycosides & $\begin{array}{l}\text { Hardly penetrate within cell, invalid to small } \\
\text { colony variants }\end{array}$ \\
\hline Fluoroquinolones & Poor intracellular accumulation \\
\hline Macrolides & Poor retention within cell \\
\hline Vancomycin & Instability, low permeability for tissue \\
\hline
\end{tabular}


resistance mechanism. The methicillin or cephalosporin resistance was conferred by the mec $\mathrm{A}$ gene and its homologous genes mec $\mathrm{B}$ and mec $\mathrm{C} .{ }^{56}$ The mecA gene encodes PBP2a or $\mathrm{PBP} 2$ ', a kind of specific penicillin-binding protein. These proteins will degrade the $\beta$-lactam ring, which confers the activity of penicillin, cephalosporin, and methicillin. Besides, mecA can spread by the chromosome cassette mec genetic element of $S$. aureus. ${ }^{57}$ Another resistance strategy of S. aureus is the efflux pump, which is able to actively effuse antimicrobial agents out of bacteria. The $S$. aureus biofilm also links with resistance. ${ }^{58}$ It was reported that the resistance of $S$. aureus in the biofilm state was enhanced because of the reduced permeability of drugs. ${ }^{59}$ Currently, the effective strategic measures involving alternative therapeutics that can reduce the resistance of $S$. aureus are imperative.

\section{Enhanced activity of antibiotics against $S$. aureus by nanoparticles}

As discussed earlier, many antibiotics are ineffective in the treatment of the infections caused by $S$. aureus due to the intelligent survival strategies and self-protection measures of $S$. aureus. The nanomedicines have been an emerging therapeutic approach to conquer the obstacles of treatment of $S$. aureus infections with their ability of inhibition of the formation of biofilm, ${ }^{60}$ penetration of cell and biofilm membrane, enhanced intracellular retention, ${ }^{61}$ and improved antibacterial activity of the loaded antimicrobial agents. Nanoparticles can passively accumulate in certain organs and infection site because of their special characteristics, such as nanosize, surface charge, and large specific surface area. The modified nanoparticles could further enhance the transmembrane performance of their payload drug by actively realizing the receptors of host cells and bacterial cells. Currently, many antimicrobial agents are incorporated into or conjugated with nanocarriers to enhance the pharmacologic activities against sensitive and resistant $S$. aureus in the SCVs and normal phenotype states and action times, and to reduce the side effects of the drug (Table 4). Therefore, nanoparticle drug delivery systems proved an ideal weapon to overcome the challenges of $S$. aureus infection that we faced.

\section{Inhibition of biofilm formation}

Because of the high permeability, nanoparticles can penetrate the thick biofilms. Bastari et al demonstrated that the nafcillin sodium and levofloxacin-loaded poly (lactide-co-glycolide) (PLGA) nanoparticles coated with calcium phosphate are able to inhibit the formation of $S$. aureus biofilm for 4 weeks. ${ }^{62}$ Thomas et al demonstrated that ciprofloxacinloaded PLGA nanoparticles were more effective against S. aureus biofilms than ciprofloxacin solution..$^{63}$ As reported earlier, tetracycline-loaded chitosan nanoparticles were more effective than free tetracycline in killing intracellular S. aureus. ${ }^{64}$ The bacillus natto antimicrobial lipopeptide carboxymethyl-loaded chitosan nanoparticles exhibited a good inhibition and scavenging effect on the $S$. aureus biofilm formation and the surface-attached bacteria growth ${ }^{65}$

Table 4 The examples of improving antibacterial effect against Staphylococcus aureus infections by nanoparticle delivery systems

\begin{tabular}{|c|c|c|c|}
\hline Antimicrobial & Nanocarriers & Performance & Reference \\
\hline Ceftazidime & Liposomes & Inhibited formation of biofilm & Zhou et al $(2012)^{67}$ \\
\hline Levofloxacin & CaP-PLGA & Inhibited formation of biofilm & Bastari et al $(2014)^{64}$ \\
\hline Ciprofloxacin & PLGA & Inhibited formation of biofilm & Thomas et al $(2016)^{63}$ \\
\hline Bacillus natto & Chitosan nano & Inhibited formation of biofilm & Jiang et al $(2017)^{65}$ \\
\hline Gold & Nanoparticles & Enhanced ablation of MRSA biofilm & Hu et al $(2017)^{70}$ \\
\hline $\mathrm{ZnO}$ & Nanosized & Decreased biofilm formation & Alves et al $(2017)^{71}$ \\
\hline Gentamicin & PLGA & Increased intracellular drug & Imbuluzqueta et al $(2010)^{73}$ \\
\hline Gentamicin & Liposomes & Enhanced level of intracellular gentamicin & Dees and Schultz $(1990)^{79}$ \\
\hline Penicillin G & Self-assembled & Better effect of penetration into cell & Sémiramoth et al $(2012)^{93}$ \\
\hline Enrofloxacin & SLNs & Increased ability of accumulation in cell & Xie et al $(2017)^{85}$ \\
\hline Silver & Nanoparticles & Enhanced effect of intracellular MRSA & Aurore et al $(2018)^{104}$ \\
\hline Vancomycin $\mathrm{HCl}$ & SLNs & Effective against MRSA infection & Kalhapure et al $(2014)^{98}$ \\
\hline Daptomycin & Liposomes & Enhanced activity of anti-MRSA & Li et al $(2015)^{99}$ \\
\hline Azithromycin & DP7-C liposomes & Higher anti-MRSA effect & Liu et al $(2016)^{100}$ \\
\hline Tilmicosin & SLNs & Better therapeutic efficacy to mastitis & Wang et al $(2012)^{106}$ \\
\hline Gold & Gold nanoclusters & Effective against MRSA infection & Xie et al $(2018)^{107}$ \\
\hline
\end{tabular}

Abbreviations: CaP, tricalcium phosphate; MRSA, methicillin-resistant Staphylococcus aureus; PLGA, poly (lactide-co-glycolide); SLN, solid lipid nanoparticle. 
It is well known that glycocalyx, the main component of bacterial biofilm, is typically anionic. ${ }^{66}$ Some cationic nanoparticles loaded with antimicrobial agents provide a new promising way to treat the infections of $S$. aureus that formed biofilm. It was reported that cationic liposomal ceftazidime could remarkably inhibit the biofilm formation of S. aureus compared with the ceftazidime solution. ${ }^{67}$ The cell membrane of $S$. aureus will be disrupted when the positively charged ions of particle bind to negatively charged groups of the bacterial membrane. This process will create pores on the membrane and result in flowing out of cytoplasmic contents from the cell and dissipating the gradient of $\mathrm{H}^{+}$across the cell membrane, which may lead to cell death. ${ }^{68,69}$

Some metal nanoparticles have been developed to effectively restrain the biofilm formation of $S$. aureus. For example, surface-adaptive gold nanoparticles exhibited enhanced photothermal ablation on MRSA biofilm under near-infrared light irradiation without injury to the healthy tissues. $^{70}$ Nanosized $\mathrm{ZnO}$ strengthened the antibacterial activity of their loaded antimicrobial agents, decreased the biofilm formation, and overcame attachment of MRSA on medical instruments in the implant-related infections. ${ }^{71}$ The metal ions can lead to bacterial cell membrane disruption and then internalization into the bacterial cytosol. The reactive oxygen species form after internalization and then lead to DNA damage and cell death. It is also reported that the nanoparticles can effectively inhibit the biofilm formation via inhibiting the QS-regulated gene expression. ${ }^{72}$

\section{Enhanced intracellular delivery}

The therapeutic effect of antimicrobial agents against intracellular $S$. aureus is dependent on the persistent time in the infected cell above the effective therapeutic levels. The drug concentration within the cell is decided by their ability of penetration into cell membrane and intracellular accumulation performance. As we all know, the nanoparticles can improve the permeability as well as accumulation of their payload drug within cells. Due to the direct effect between the particles and $S$. aureus in contact with them and the diffusion of the released drugs to $S$. aureus, the increased cellular uptake and subsequent controlled release of the nanoparticle entrapped/adsorbed antibiotics can effectively enhance their antibacterial effects, which make it more effective to treat intracellular infection. For instance, PLGA nanoparticles can increase the intracellular gentamicin and improve subcellular distribution, thus demonstrating stronger antibacterial effect against $S$. aureus. ${ }^{73}$ The polymeric nanoparticles with ionic core and specific hydrophobic/hydrophilicity chemistry of the shell can also produce promising action against bacteria via interaction with cell membrane by hydrophobic segment of shell and stronger electrostatic interaction with the opposite surface charge of the core. It was reported that the modified nanoparticles with specific ligands of macrophage can enhance the phagocytosis efficiency for improving the intracellular concentration of antimicrobial agents. ${ }^{74}$ Chakraborty et al discovered that vancomycin chitosan folic acid nanoparticles showed more effective performance across the epithelial and bacterial cell surfaces and stronger anti-S. aureus effect compared to the chitosan nanoparticles. ${ }^{75}$

Liposomes are also viewed as a prospective carrier for intracellular delivery of antimicrobial agents due to their phospholipid bilayer structure being just like a cell membrane, meaning the phospholipid bilayer structure can easily bind other groups so that it can be designed responsively to secreted bacterial toxins. Gupta et al demonstrated that levofloxacin liposomes exhibited prolonged, improved antibiofilm and antimicrobial efficacy in treating $S$. aureus infection. ${ }^{76}$ Recently, it was confirmed that chloramphenicolloaded deoxycholic acid liposomes can increase antibacterial effect on keratinocyte-infected MRSA and that the deformable liposomes hold excellent biocompatibility. ${ }^{77}$ It was reported that the compound of vancomycin-loaded liposome surface bounded with chitosan-modified gold nanoparticles has the ability of responding to bacterial toxins. ${ }^{78}$ The liposomes were also proved to enhance the intracellular gentamicin and antibacterial activity against $S$. aureus. ${ }^{79}$ Ahani et al also indicated that polyhexamethylene biguanide chloride cationic liposome enables delivery of high concentrations of the antibacterial agent into the infectious cell and lower cytotoxicity. ${ }^{80}$ Bas et al reported that the intracellular concentration of liposomal ofloxacin can reach up to 2.6-fold that of free ofloxacin. ${ }^{81}$ A study reported that enrofloxacin load liposomes can inhibit the $S$. aureus in neutrophils for 60 minutes. $^{82}$ It was reported that the chitosan-decorated liposome containing alpha-lipoic acid and coenzyme $\mathrm{Q}_{10}$ also showed strong bactericidal effect with $S$. aureus. This new measure with multiple antimicrobial mechanisms will be a potential approach for reducing the resistance development of $S$. aureus. ${ }^{83}$ In addition, aimed at the higher temperature of the infected site than the healthy tissue, a kind of antibioticloaded thermally sensitive liposome that can release completely at $\geq 39^{\circ} \mathrm{C}$ was designed, and it showed significant ability of killing $S$. aureus at $42^{\circ} \mathrm{C}$ than at $37^{\circ} \mathrm{C} .{ }^{84}$

Solid lipid nanoparticles (SLNs) might be another promising drug delivery system with the distinct advantages of biodegradability, good biocompatibility, and stability. 
Our previous work also showed that enrofloxacin-loaded docosanoic acid SLNs could effectively increase the accumulation and storage time of enrofloxacin within the cell. ${ }^{85}$ The cellular uptake and accumulation of payload enrofloxacin are influenced by the zeta potential and diameter of the nanoparticles.

Some inorganic nanoparticles also showed huge potential for the $S$. aureus infection treatment. For example, $\beta$-tricalcium phosphate nanoparticles have made great achievements in osteomyelitis of $S$. aureus because of the stimulation bone regeneration function of $\beta$-tricalcium phosphate. ${ }^{86,87}$ The phagocytosed number of ciprofloxacinloaded niosomes was much more than free ciprofloxacin and showed higher antimicrobial activity against intracellular S. aureus. ${ }^{88}$

The antibacterial activity of nanoparticles is determined by its stability to the infected cells and the arrival in the target subcellular site in a predetermined way. The nanoparticles hold different transport routes into cells including phagocytosis (zipper-like and trigger-like) and nonphagocytosis $^{89}$ (Figure 3 ). The different transport routes could influence the cellular uptake and intracellular distribution, thus influencing the therapy effects. Most uptake ways, that is, clathrin-mediated endocytosis, trigger-like phagocytosis, and macropinocytosis, mainly gather in the late endosomes and/or finally lysosomes to form an endolysosome (phagolysosome), and thus the internalized nanoparticles are often stored at acidic environments of endosomes and/or lysosomes and/or endolysosome (phagolysosome) ${ }^{90}$ This transcellular way will be used to fight against $S$. aureus accumulated in phagosomes/phagolysosomes (endosomes/endolysosomes) and help to increase the antimicrobial effect of diffusible drug against cytoplasmic $S$. aureus or vesicles containing S. aureus. The endosomotropic/lysosomotropic trafficking might be highly effective against $S$. aureus because the main intracellular parasitic sites of $S$. aureus were phagosome and cytoplasm..$^{28}$ Besides, lysosomotropic or/and endosomotropic transports (ie, CvME, zipper-like phagocytosis) also might be an alternative way for intracellular antimicrobial agent delivery due to the ability to bypass lysosomes. Therefore, the non-lysosomotropic transports may be helpful for intracellular delivery of antibiotics that are hypersensitive to lysosomal enzymes and to kill the pathogen invaded in the similar pathways as bacteria. ${ }^{91,92}$

The transmembrane pathways and mechanism of nanoparticles depended on the size, zeta potential, surface hydrophilicity, and shape of nanoparticles. The clathrin-mediated endocytosis mainly aimed at the nanoparticles with size range from 100 to $200 \mathrm{~nm}$. Therefore, 100-200 nm nanoparticles may have better intracellular colocalization with $S$. aureus by



Figure 3 The mechanism of nanoparticle intracellular transport. 
the clathrin-mediated endocytosis. For example, Sémiramoth et al proved that penicillin $G$ self-assembled nanoparticles with a size of $140 \pm 10 \mathrm{~nm}$ displayed stronger penetration into cell through clathrin-dependent than free penicillin $G$ and showed enhanced antibacterial activity against intracellular S. aureus. ${ }^{93}$ In addition, the charge is also an important element that will influence the uptake of nanoparticle. The nanoparticles with either negative or positive charge appear to have more efficient endocytosis than the neutral nanoparticles. ${ }^{94}$ The constituent of nanoparticle plays a key effect on uptake ways in that it determines the surface properties of nanoparticles. Generally, the hydrophilicity/hydrophobicity will influence the opsonization and phagocytosis, and thus determine the fate of exogenous nanoparticles in vivo. The surface hydrophobicity seems to be an important factor for enhanced uptake of nanoparticles. Couvreur et al showed that PEGylation of nanoparticles decreases the macrophage uptake. ${ }^{95}$ Recently, the controlling phagocytosis via shape change of nanoparticle is more increasingly focused on. Beningo et al declared that rigid polyacrylamide nanoparticles were more easily uptaken than the soft ones because they were able to stimulate the assembly of actin filaments, which are required for the formation and closure of phagosomes. ${ }^{96}$

\section{Improved activity against MRSA}

The resistance is one of the major barriers for fighting against the $S$. aureus infection, especially for MRSA. Facing the situation that the evolution of pathogens and resistance production of $S$. aureus are faster than the discovery and development of new drugs, the active recovery of existing antibiotics using the pharmaceutical technologies will be a potential strategy. Recently, nanomedicines were viewed as a promising measure to overcome the problem of MRSA. ${ }^{97}$ It is reported that vancomycin $\mathrm{HCl}-\mathrm{SLNs}$ displayed a more effective and longer effect on the resistant and sensitive S. aureus than vancomycin HCL. ${ }^{98}$ Liposomes' codelivery of clarithromycin and daptomycin with a mass ratio of 1:32 demonstrated an enhanced anti-MRSA activity and increased the survival of the infected host cells compared to the liposomal daptomycin and liposomal clarithromycin, respectively. ${ }^{99}$ Antibiotics-loaded nanoparticles might hold high permeability to MRSA because of their small particle size. It is well known that nanoparticles have positive or negative surface charge itself or by decoration. The surface charge is convenient for the adsorbing of nanoparticles on the surface of MRSA and then contributed to express high antibacterial activity of antimicrobial agents. Besides the antimicrobial agents, the carrier materials (metal ion, lipids, and hydrogels) also have the antibacterial activity. The multiple bactericidal mechanisms (metal ion release, oxidative stress induction, DNA or ribonucleic acid damaging, and cell membrane disruption) require multiple gene mutations simultaneously, and therefore the resistance of bacteria is avoided or produced difficultly.

Some researchers focus on the modification of nanoparticles to further enhance the effects of antimicrobial agents against MRSA. For example, Chol-suc-VQWRIRVAVIRK$\mathrm{NH}_{2}$ (DP7-C)-modified liposomes payload azithromycin showed higher anti-MRSA effect in mouse model compared to liposomal and free azithromycin via the upregulation of anti-inflammatory cytokines and chemokines. ${ }^{100}$ It is more meaningful for $\mathrm{pH}$-sensitive nanoparticles to combat the resistance ${ }^{101}$ because $S$. aureus can produce acidity at infection sites. ${ }^{102}$ Some nanoparticle materials and modification of nanoparticles can make the nanoparticles $\mathrm{pH}$ sensitive. The nanoparticles will release drugs quickly in acid environment of the infection site of MRSA, thus achieving strong activity. ${ }^{103}$

Metal nanoparticles are being tried to overcome the resistance of MRSA based on the different antibacterial activities of metals and the unique nature of nanoparticles. For example, Aurore et al found that nano-silver displayed excellent antibacterial activity against intracellular MRSA in osteoclasts at the level of nontoxic concentration and thus showed potential measures for bone infection treatment. ${ }^{104}$ There are some controversies that the metal ion might enhance the resistance of bacteria. In the future, it will be possible for the combination of existing nanoparticles and modified technology to further improve the activity of antibiotics against resistant $S$. aureus and make them to be widely used in clinics.

\section{Improved activity against SCV phenotypes}

The typical characteristics of SCV phenotype are the lower metabolism level and growth rate than the normal phenotype, which makes the $S$. aureus difficult to detect by the immune system and difficult to destroy by antimicrobial agents. Some researchers are trying to enhance the activity of antibacterial agents against SCV phenotypes of $S$. aureus. Richter et al proved that protoporphyrin and defriprone can increase the activity of antibiotics against SCVs of $S$. aureus, because of their ability of increasing the cell metabolism level. ${ }^{105}$ The agents that can increase cell metabolism will be a new approach for solving the therapy challenges of SCVs by using them to modify the nanoparticles. 


\section{Enhanced therapeutic efficiency in vivo}

It will be easier to accumulate the nanoparticles in the infection foci in the body via the phagocytic cells of the mononuclear phagocytic system (MPS) and local impaired lymphatic drainage and enhanced capillary permeability due to the inflammation. In these processes, there are more opportunities that nanoparticles can meet the intracellular and extracellular S. aureus. Many studies demonstrated that the nanoparticles can enhance the treatment efficiency of antimicrobial agents against $S$. aureus infections in vivo. For example, tilmicosinloaded hydrogenated castor oil SLNs with lower dosage showed better therapeutic efficacy than free tilmicosin for $S$. aureus mastitis infection in mice due to the enhanced bioavailability and sustained-release performance. ${ }^{106} \mathrm{Xie}$ et al proved that the gold nanoclusters showed excellent therapeutic effect on both the bacteremia model and the skin infection model induced by MRSA, due to the reasonable circulation time and the ultra-small size of the nanoclusters. ${ }^{107}$ It was reported that the anti-MRSA activity of vancomycin $\mathrm{pH}$-responsive lipid nanoparticles was 1.8 -fold higher than vancomycin in vivo. ${ }^{108}$ In addition, some inorganic materials with good biologic activities and low toxicity (vanadium dioxide) ${ }^{109}$ also showed satisfactory effects on $S$. aureus infections in vivo. For example, the silica nanoprobe coated with vancomycin and decorated with polyelectrolyte-cypate complexes can selectively enable rapid (4 hours postinjection) near infrared fluorescence imaging with high sensitivity $\left(10^{5}\right.$ colony-forming units) and achieve efficient photothermal therapy of MRSA infections in mice. Remarkably, the nanoprobes can afford a long-term tracking (16 days) of MRSA infection changes. ${ }^{110}$ The bacteria-responsive functional nanomaterials will offer chance to combat the infections of bacterial resistance. The nanohydrogel systems were also considered as an effective medium to cope with the challenges of $S$. aureus because of the strong adhesiveness to infection site, sustained drug release, reduced frequency of dosage, and excellent inhibition of bacterial growth. Nimal et al found that chitosan gel containing tigecycline nanoparticle displayed significant activities against $S$. aureus using a Drosophila melanogaster infection model. ${ }^{11}$

\section{Current challenges}

Nanoparticles armed with antimicrobial agents are used as a potential weapon against $S$. aureus infection due to their specific biologic performance, and have shown more advantages than the traditional preparations. But the studies of nanosystems against $S$. aureus infections are not complete and we still face the challenges from nanosystems, reasonable largescale production, and so on. There are some contradictions between the absence of enhanced activity against intracellular pathogens and intracellular accumulation of some antibacterial drugs through nanoparticles because of the dormant or quiescent state of bacteria ${ }^{112,113}$ and the drug inactivation in the intracellular unfavorable environment. Compared to the free rifampin, the activity against mycobacterium was not enhanced by the polyisobutyl cyanoacrylate nanoparticle, although the amount of intracellular rifampin was increased by the nanoparticles. ${ }^{114}$ The SCV phenotype of S. aureus holds lower metabolism level and growth rate than the normal phenotype, because of which the antimicrobial agents hardly kill them. Currently, nanoparticles are scarcely developed to fight against the SCV phenotype of $S$. aureus. To eliminate the persisting SCV phenotype, establishing new approaches for development of nanoparticles is necessary. Combination treatment, either through the incorporation of multiple antibacterial agents that have synergistic effects, or the combined use of antibiotics and other intervention drugs with different antibacterial mechanisms, may be a promising way to combat the quiescence or dormancy of $S$. aureus. Another major challenge that we are facing is the premature release of nanoparticles. The key issue in the successful treatment of intracellular S. aureus with biofilm and drug resistance is the stability of the nanoparticles in transport, that is, it is important to ensure that the nanoparticles have not prematurely released the drug before reaching the nidus and that the drug inactivation on the way is avoided. Unfortunately, nanoparticles with an ideal ability to reach the target site without premature drug release are hardly achieved. Another insurmountable challenge is to make use of the nanoparticle payload antimicrobial agents to counteract MPS externally localized intracellular infections. As we all know, uptake by mononuclear phagocytes is highly beneficial in treating MPS infections. However, S. aureus can infect nonprofessional phagocytes, that is, enterocytes, hepatocytes, fibroblasts, and epithelial cells. The low phagocytic capacity of these cells prevents the $S$. aureus in the infected non-MPS tissues from being targeted. Therefore, the current antimicrobial agent nanoparticle systems should be endowed with the performance of distinguishing between the infected and the healthy cells and tissues, and have specific drug release according to the affected environment. Currently, the performance of antibacterial drug-loaded nanoparticles is evaluated in vitro and in vivo. Because of the transportation complexity and unpredictability of nanoparticles in vivo, the clinical efficacy of nanoparticles is still suspect, and their clinical evaluation should be strengthened. 
Table $\mathbf{5}$ The disadvantages of various nanoparticle drug delivery systems

\begin{tabular}{l|l}
\hline Drug delivery system & Disadvantages \\
\hline Liposomes & Low capacity, instability \\
\hline Lipid nanoparticles & Premature release \\
\hline Polymeric nanoparticles & Low loading capacity \\
\hline$\beta-T C P$ nanoparticles & Low encapsulation efficiency \\
\hline
\end{tabular}

Abbreviation: $\beta$-TCP, $\beta$-tricalcium phosphate.

As far as the nanoparticles are concerned, they should be nontoxic, highly loading, of low cost, and capable of reproducible manufacturing and validated characterization in order to achieve better clinical application. Unfortunately, current nanoparticle delivery systems seldom achieve these requirements (Table 5). For example, the poor drug loading capacity and instability of the liposomes remain important issues ${ }^{41}$ Low loading capacity of polymeric nanoparticles for the polar antimicrobial agents is always faced due to the mutual repulsion between the hydrophilic active molecules and the hydrophobic polymers. The lack of reasonable large-scale production is still another bottleneck for polymeric nanoparticles. Although SLNs overcome some disadvantages of liposomes and polymeric nanoparticles, the loading capacity and premature release are still the major challenges. There is no selectivity for metal ion nanoparticles to eukaryotic cells and bacterial cells, so effective transport of these nanoparticles to infected site must be a focus. ${ }^{115}$ Other nanoparticles, that is, $\beta$-tricalcium phosphate nanoparticles, are also beset by these problems. The loading capacity as well as the stability of nanoparticles are being improved by the modification and the combination of various advantages of different nanoparticles. For example, a novel complex drug nanocarrier that combined the technologies of inorganic (hydroxyapatite) and organic nanomaterials (chitosan/konjac glucomannan) and liposomes offered high loading capacity, sustained release profiles, and strong activity against biofilms of $S$. aureus compared with free vancomycin. ${ }^{116}$ The multifunctional nanoparticle delivery systems with definite clinical efficacy, affordability, and good compliance should be developed to avoid the disadvantages of current nanoparticles and to possess combined advantages of various nanosystems.

\section{Future perspectives}

Facing the therapeutic challenges of $S$. aureus infections, we have to discover and develop more new nanosystem methods in order to effectively treat the $S$. aureus infections. As mentioned earlier, S. aureus can live both in extracellular and different subcellular structures. The intracellular efficacy of nanoparticles not only depends on the release of antimicrobial agents and high cell-associated drug levels but also the localization between drugs and intracellular bacteria. ${ }^{90}$ Currently, the research focuses on whether the antimicrobials could penetrate membrane into cells but seldom on the drug delivery and release in the subcellular structure. The intracellular colocalization of different nanoparticles with $S$. aureus via the change in its physicochemical properties and proper modification should be strengthened to achieve the better colocalization between drugs and intracellular S. aureus and thus achieve satisfactory therapy.

It is well known that the $\mathrm{pH}$ of the infected site and the intracellular environment is lower than those of the healthy tissue and the extracellular environment, respectively. It is more promising for $\mathrm{pH}$-sensitive nanoparticles to combat the infection of S. aureus. ${ }^{117}$ Among various nanoparticles, the nanogel is $\mathrm{pH}$-dependent and will be possible for targeted therapy of S. aureus infection. The loaded drug release of nanogel is more rapid in lower $\mathrm{pH}$. It was reported that the nanogel was released in a small amount of their payload antimicrobial agents in the milk of the infected mammary gland with a $\mathrm{pH}$ of 7.0 7.4, while it was released quickly and completely in the lower $\mathrm{pH}$ value (5.0 5.5) of the intracellular endosomes and lysosomes where the $S$. aureus resided. ${ }^{118,119}$ In addition, nanogel can adhere to the mammary gland for a long time, because of the strong mucous adhesiveness, and penetrate into the mammary epithelial cell easily due to the small size, larger surface power, and stronger bioadhesion of gel material (eg, sodium alginate, chitosan). These merits will contribute to transporting of their payload drug into the infected sites and cells. Therefore, the nanogel will be an effective weapon to achieve the target treatment for S. aureus and should be given more attention (Figure 4), especially for the nanogel combined with other nanoparticles.

Facing the situation that the evolution of pathogens and resistance production of pathogenic bacteria are faster than the discovery and development of new drugs, the nanoparticle delivery systems with multiple bactericidal mechanisms, eg, coating or conjugation antimicrobial agents via antimicrobial peptides and antibacterial enzymes, should be put on a high level. ${ }^{120,121}$ In addition, conventional antimicrobial agents or treatment measures may not be able to completely remove all bacteria and thus lead to the bacterial persistence after treatment. The challenges from biofilms and SCVs of $S$. aureus are still difficult to cope with. In the future, the antimicrobial photodynamic therapy (APDT) and photon-induced photoacoustic streaming (PIPS) should be paid more attention. It is reported that APDT and PIPS combined with nanoparticles may destroy the functional integrity of bacterial cell walls, DNA, biofilm, and membrane proteins of bacteria. ${ }^{122-124}$ Shrestha et al found that APDT with chitosan-conjugated 


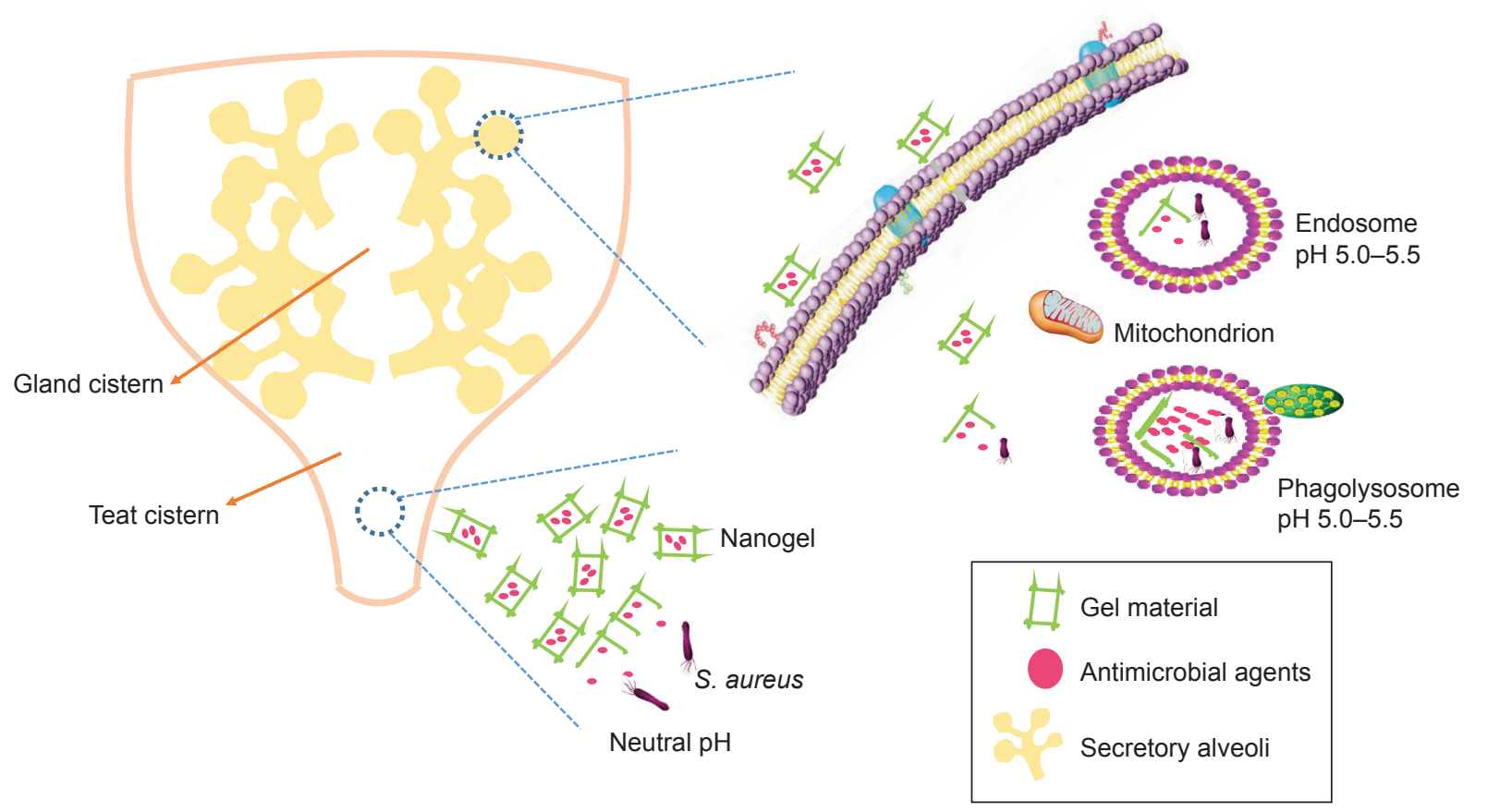

Figure 4 The mechanism of nanogel releasing drug in the mammary. Abbreviation: S. aureus, Staphylococcus aureus.

rose bengal nanoparticles (CSRBnps) achieved endotoxin inactivation and cleaned all the tested inflammatory factors from macrophages. The CSRBnps with APDT showed the ability to effectively inactivate endotoxins. ${ }^{125}$
Nanoparticle-mediated antimicrobial drug delivery is a multiple and intricate dynamic process in vivo, including the absorption, distribution, metabolism, excretion, and drug release. The dynamic process can influence the uptake

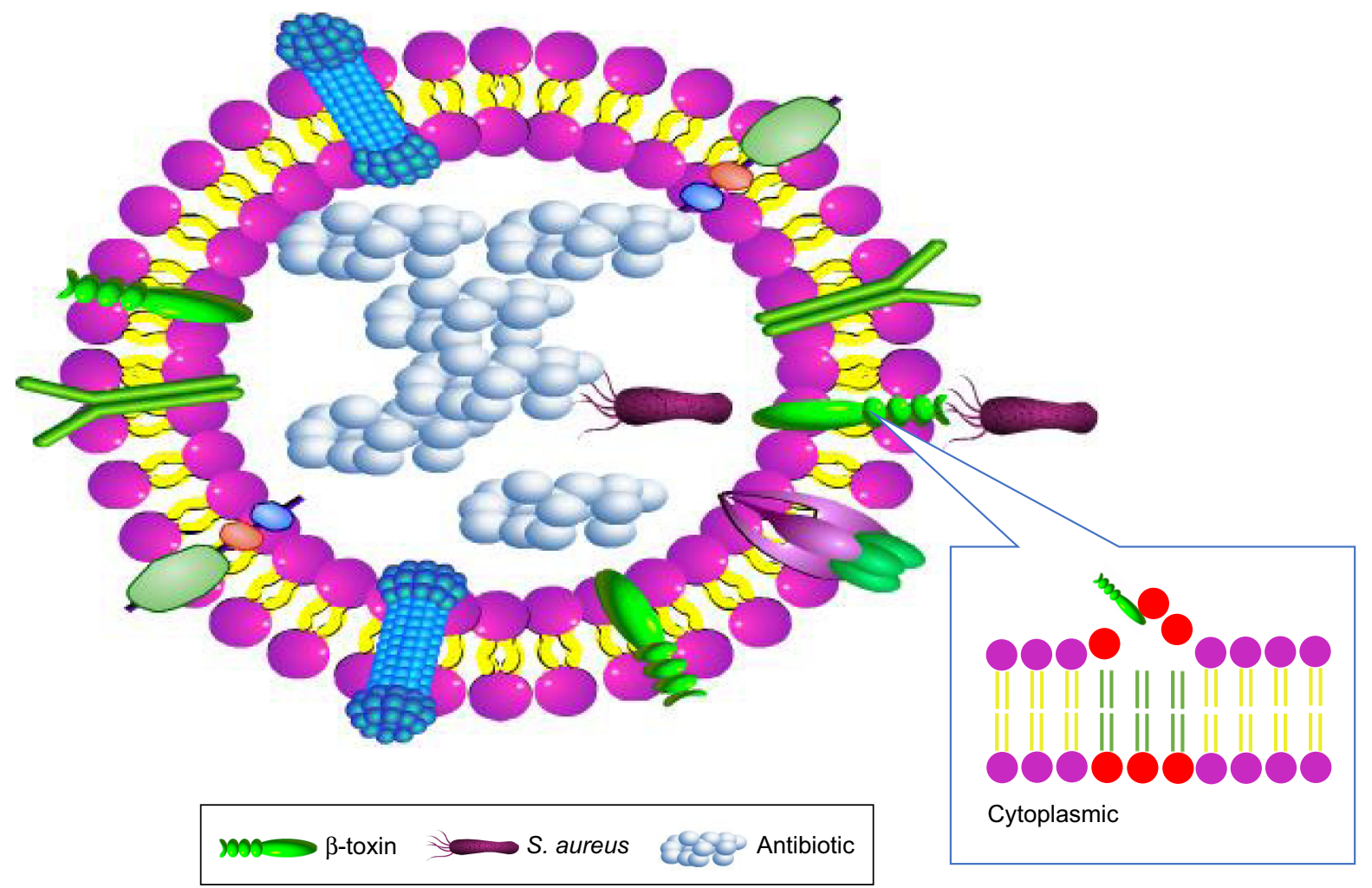

Figure $\mathbf{5}$ The process of Staphylococcus aureus entering cell membrane-coated nanoparticle. Abbreviation: S. aureus, Staphylococcus aureus. 
rate and fate of nanoparticles and their payload drugs. Therefore, the thorough studying of the dynamic process of nanoparticles in the cells and tissues as well as the invasion mechanism of $S$. aureus is a prerequisite to develop appropriate nanosystems for effective $S$. aureus infection therapy. In the future, the smart nanosystems with simulated invasion mechanism of $S$. aureus and simultaneously aimed at intracellular $S$. aureus, $S$. aureus with biofilm, and resistant $S$. aureus should be developed by studying the transformation mechanisms of nanoparticles at molecular, cellular, and animal levels to achieve the satisfactory effects. The smart nanoparticles aimed at the invasion process of $S$. aureus should be developed to improve the therapy effects of $S$. aureus infection disease. The erythrocyte membrane-coated nanogel (red erythrocyte membrane-coated [RBC]-nanogel) system using as a "trap" was discovered according to the features of penetration of cell membrane of $S$. aureus (Figure 5). ${ }^{126}$ The RBC-nanogel can use the loaded antimicrobial agents to kill $S$. aureus when the bacteria realize specific receptors of erythrocyte membrane and then enter into RBC-nanogel by secreting $\beta$-toxin and $\delta$-toxin.

\section{Acknowledgments}

This work was supported by the National Natural Science Foundation of China (grant no 31772797).

\section{Disclosure}

The authors report no conflicts of interest in this work.

\section{References}

1. von Eiff C, Becker K, Machka K, Stammer H, Peters G. Nasal carriage as a source of Staphylococcus aureus bacteremia. Study Group. N Engl J Med. 2001;344(1):11-16.

2. Chambers HF. The changing epidemiology of Staphylococcus aureus? Emerg Infect Dis. 2001;7(2):178-182.

3. Rasmussen G, Monecke S, Brus O, Ehricht R, Söderquist B. Long term molecular epidemiology of methicillin-susceptible Staphylococcus aureus bacteremia isolates in Sweden. PLoS One. 2014;9(12): e114276.

4. Posadowska U, Brzychczy-Włoch M, Pamuła E, Perl TM, Cullen JJ, Wenzel RP. Gentamicin loaded PLGA nanoparticles as local drug delivery system for the osteomyelitis treatment. Acta Bioeng Biomech. 2015;17(3):41-48.

5. Gordon RJ, Lowy FD. Pathogenesis of methicillin-resistant Staphylococcus aureus infection. Clin Infect Dis. 2008;46 Suppl 5:S350-S359.

6. Conlon BP. Staphylococcus aureus chronic and relapsing infections: evidence of a role for persister cells. Bioessays. 2014;36(10): 991-996.

7. Zhou J, Fang T, Wang Y. The controlled release of vancomycin in gelatin/B-TCP composite scaffolds. J Biomed Mater Res. 2012;100A(9): 2295-2301

8. Banbury MK. Experience in prevention of sternal wound infections in nasal carriers of Staphylococcus aureus. Surgery. 2003;134(5 Suppl): S18-S22.
9. Michael IO, Gabriel OE. Pattern of renal diseases in children in midwestern zone of Nigeria. Saudi J Kidney Dis Transpl. 2003;14(4): 539-544.

10. Boucher HW, Talbot GH, Benjamin DK, et al. 10 x '20 Progressdevelopment of new drugs active against gram-negative bacilli: an update from the Infectious Diseases Society of America. Clin Infect Dis. 2013;56(12):1685-1694.

11. Jagielski T, Puacz E, Lisowski A, et al. Short communication: antimicrobial susceptibility profiling and genotyping of Staphylococcus aureus isolates from bovine mastitis in Poland. J Dairy Sci. 2014; 97(10):6122-6128.

12. Melchior MB, Vaarkamp H, Fink-Gremmels J. Biofilms: a role in recurrent mastitis infections? Vet J. 2006;171(3):398-407.

13. Halasa T, Huijps K, Østerås O, Hogeveen H. Economic effects of bovine mastitis and mastitis management: a review. Vet Q. 2007;29(1): $18-31$.

14. Loiselle MC, Ster C, Talbot BG, et al. Impact of postpartum milking frequency on the immune system and the blood metabolite concentration of dairy cows. J Dairy Sci. 2009;92(5):1900-1912.

15. Clement S, Vaudaux P, Francois $P$, et al. Evidence of an intracellular reservoir in the nasal mucosa of patients with recurrent Staphylococcus aureus rhinosinusitis. J Infect Dis. 2005;192(6):1023-1028.

16. Kerrn MB, Struve C, Blom J, Frimodt-Møller N, Krogfelt KA. Intracellular persistence of Escherichia coli in urinary bladders from mecillinamtreated mice. J Antimicrob Chemother. 2005;55(3):383-386.

17. Monack DM, Mueller A, Falkow S. Persistent bacterial infections: the interface of the pathogen and the host immune system. Nat Rev Microbiol. 2004;2(9):747-765.

18. Freeman AF, Holland SM. Persistent bacterial infections and primary immune disorders. Curr Opin Microbiol. 2007;10(1):70-75.

19. Prajsnar TK, Cunliffe VT, Foster SJ, Renshaw SA. A novel vertebrate model of Staphylococcus aureus infection reveals phagocytedependent resistance of zebrafish to non-host specialized pathogens. Cell Microbiol. 2008;10(11):2312-2325.

20. Löffler B, Tuchscherr L, Niemann S, Peters G. Staphylococcus aureus persistence in non-professional phagocytes. Int $J$ Med Microbiol. 2014;304(2):170-176.

21. Speziale P, Pietrocola G, Rindi S, et al. Structural and functional role of Staphylococcus aureus surface components recognizing adhesive matrix molecules of the host. Future Microbiol. 2009;4(10):1337-1352.

22. Zecconi A, Scali F. Staphylococcus aureus virulence factors in evasion from innate immune defenses in human and animal diseases. Immunol Lett. 2013;150(1-2):12-22.

23. Clarke SR, Brummell KJ, Horsburgh MJ, et al. Identification of in vivo-expressed antigens of Staphylococcus aureus and their use in vaccinations for protection against nasal carriage. J Infect Dis. 2006; 193(8):1098-1108.

24. Garzoni C, Kelley WL. Staphylococcus aureus: new evidence for intracellular persistence. Trends Microbiol. 2009;17(2):59-65.

25. Foster TJ, Geoghegan JA, Ganesh VK, Höök M. Adhesion, invasion and evasion: the many functions of the surface proteins of Staphylococcus aureus. Nat Rev Microbiol. 2014;12(1):49-62.

26. Bank TL, Dosen A, Giese RF, Haase EM, Sojar HT. Atomic force spectroscopy evidence of non-specific adhesion of Aggregatibacter actinomycetemcomitans. J Nanosci Nanotechnol. 2011;11(10):8450-8456.

27. Harraghy N, Hussain M, Haggar A, et al. The adhesive and immunomodulating properties of the multifunctional Staphylococcus aureus protein Eap. Microbiology. 2003;149(Pt 10):2701-2707.

28. Fraunholz M, Sinha B. Intracellular Staphylococcus aureus: live-in and let die. Front Cell Infect Microbiol. 2012;2:43.

29. Torres VJ, Pishchany G, Humayun M, Schneewind O, Skaar EP. Staphylococcus aureus IsdB is a hemoglobin receptor required for heme iron utilization. J Bacteriol. 2006;188(24):8421-8429.

30. Rasmussen G, Monecke S, Brus O, Ehricht R, Söderquist B. Long term molecular epidemiology of methicillin-susceptible Staphylococcus aureus bacteremia isolates in Sweden. PLoS One. 2014; 9(12):e114276. 
31. Wilke GA, Bubeck Wardenburg J, Wardenburg JB. Role of a disintegrin and metalloprotease 10 in Staphylococcus aureus alphahemolysin-mediated cellular injury. Proc Natl Acad Sci U S A. 2010; 107(30):13473-13478.

32. Grosz M, Kolter J, Paprotka K, et al. Cytoplasmic replication of Staphylococcus aureus upon phagosomal escape triggered by phenol-soluble modulin $\alpha$. Cell Microbiol. 2014;16(4):451-465.

33. Garzoni C, Kelley WL. Staphylococcus aureus: new evidence for intracellular persistence. Trends Microbiol. 2009;17(2):59-65.

34. Kahl BC. Small colony variants (SCVs) of Staphylococcus aureus a bacterial survival strategy. Infect Genet Evol. 2014;21:515-522.

35. Tuchscherr L, Medina E, Hussain M, et al. Staphylococcus aureus phenotype switching: an effective bacterial strategy to escape host immune response and establish a chronic infection. EMBO Mol Med. 2011 3(3):129-141.

36. Tuchscherr L, Geraci J, Löffler B. Staphylococcus aureus regulator Sigma B is important to develop chronic infections in hematogenous murine osteomyelitis model. Pathogens. 2017;6(3):E31.

37. Proctor RA, Balwit JM, Vesga O. Variant subpopulations of Staphylococcus aureus as cause of persistent and recurrent infections. Infect Agents Dis. 1994;3(6):302-312.

38. Sendi P, Proctor RA. Staphylococcus aureus as an intracellular pathogen: the role of small colony variants. Trends Microbiol. 2009; 17(2):54-58.

39. Bui LMG, Kidd SP. A full genomic characterization of the development of a stable small colony variant cell-type by a clinical Staphylococcus aureus strain. Infect Genet Evol. 2015;36:345-355.

40. Tuchscherr L, Heitmann V, Hussain M, et al. Staphylococcus aureus small-colony variants are adapted phenotypes for intracellular persistence. J Infect Dis. 2010;202(7):1031-1040.

41. Ou JJ, Drilling AJ, Cooksley C, et al. Reduced innate immune response to a Staphylococcus aureus small colony variant compared to its wildtype parent strain. Front Cell Infect Microbiol. 2016;6:187.

42. Serra R, Grande R, Buffone G, et al. Extracellular matrix assessment of infected chronic venous leg ulcers: role of metalloproteinases and inflammatory cytokines. Int Wound J. 2016;13(1):53-58.

43. Looney WJ. Small-colony variants of Staphylococcus aureus. Br J Biomed Sci. 2000;57(4):317-322.

44. Besier S, Ludwig A, Ohlsen K, Brade V, Wichelhaus TA. Molecular analysis of the thymidine-auxotrophic small colony variant phenotype of Staphylococcus aureus. Int J Med Microbiol. 2007;297(4):217-225.

45. Amato SM, Fazen CH, Henry TC, et al. The role of metabolism in bacterial persistence. Front Microbiol. 2014;5:70.

46. Bassegoda A, Ivanova K, Ramon E, Tzanov T. Strategies to prevent the occurrence of resistance against antibiotics by using advanced materials. Appl Microbiol Biotechnol. 2018;102(5):2075-2089.

47. Oyama T, Miyazaki M, Yoshimura M, Takata T, Ohjimi H, Jimi S. Biofilm-forming methicillin-resistant Staphylococcus aureus survive in kupffer cells and exhibit high virulence in mice. Toxins. 2016 8(7):198.

48. Armstead AL, Li B. Nanomedicine as an emerging approach against intracellular pathogens. Int J Nanomedicine. 2011;6:3281-3293.

49. Limbert $\mathrm{M}$, Isert $\mathrm{D}$, Klesel $\mathrm{N}$, et al. Antibacterial activities in vitro and in vivo and pharmacokinetics of cefquinome (HR $111 \mathrm{~V}$ ), a new broad-spectrum cephalosporin. Antimicrob Agents Chemother. 1991; 35(1):14-19.

50. Briones E, Colino CI, Lanao JM. Delivery systems to increase the selectivity of antibiotics in phagocytic cells. J Control Release. 2008; 125(3):210-227.

51. Pinto-Alphandary H, Andremont A, Couvreur P. Targeted delivery of antibiotics using liposomes and nanoparticles: research and applications. Int J Antimicrob Agents. 2000;13(3):155-168.

52. Taber WH, Mueller JP, Miller PF. Bacterial uptake of aminoglycoside antibiotics. Micro Rev. 1987;51(4):439-457.

53. Bui LM, Conlon BP, Kidd SP. Antibiotic tolerance and the alternative lifestyles of Staphylococcus aureus. Essays Biochem. 2017;61(1): 71-79.
54. Gómez Casanova N, Siller Ruiz M, Muñoz Bellido JL. Mechanisms of resistance to daptomycin in Staphylococcus aureus. Rev Esp Quimioter. 2017:30(6):391-396.

55. Gardete S, Tomasz A. Mechanisms of vancomycin resistance in Staphylococcus aureus. J Clin Invest. 2014;124(7):2836-2840.

56. Becker K, Ballhausen B, Köck R, Kriegeskorte A. Methicillin resistance in Staphylococcus isolates: the "mec alphabet" with specific consideration of $m e c C$, a mec homolog associated with zoonotic $S$. aureus lineages. Int J Med Microbiol. 2014;304(7):794-804.

57. Deurenberg RH, Stobberingh EE. The molecular evolution of hospitaland community-associated methicillin-resistant Staphylococcus aureus. Curr Mol Med. 2009;9(2):100-115.

58. Hall-Stoodley L, Stoodley P. Evolving concepts in biofilm infections. Cell Microbiol. 2009;11(7):1034-1043.

59. Singh R, Ray P, Das A, Sharma M. Role of persisters and small-colony variants in antibiotic resistance of planktonic and biofilm-associated Staphylococcus aureus: an in vitro study. J Med Microbiol. 2009; 58(Pt 8):1067-1073.

60. Park SB, Steadman CS, Chaudhari AA, et al. Proteomic analysis of antimicrobial effects of pegylated silver coated carbon nanotubes in Salmonella enterica serovar Typhimurium. J Nanobiotechnology. 2018; 16(1):31.

61. Yazar E, Bas AL, Birdane YO, Yapar K, Elmas M, Tras B. Determination of intracellular (neutrophil and monocyte) concentrations of free and liposome encapsulated ampicillin in sheep. Veterinární Medicína. 2012;51(No 2):51-54.

62. Bastari K, Arshath M, Ng ZH, et al. A controlled release of antibiotics from calcium phosphate-coated poly(lactic-co-glycolic acid) particles and their in vitro efficacy against Staphylococcus aureus biofilm. J Mater Sci Mater Med. 2014;25(3):747-757.

63. Thomas N, Thorn C, Richter K, Thierry B, Prestidge C. Efficacy of poly-lactic-co-glycolic acid micro- and nanoparticles of ciprofloxacin against bacterial biofilms. J Pharm Sci. 2016;105(10):3115-3122.

64. Maya S, Indulekha S, Sukhithasri V, et al. Efficacy of tetracycline encapsulated O-carboxymethyl chitosan nanoparticles against intracellular infections of Staphylococcus aureus. Int J Biol Macromol. 2012 ; 51(4):392-399.

65. Jiang XH, Zhou WM, He YZ, Wang Y, Lv B, Wang XM. Effects of lipopeptide carboxymethyl chitosan nanoparticles on Staphylococcus aureus biofilm. J Biol Regul Homeost Agents. 2017;31(3):737-743.

66. Sutherland IW. The biofilm matrix - an immobilized but dynamic microbial environment. Trends Microbiol. 2001;9(5):222-227.

67. Zhou TH, Su M, Shang BC, et al. Nano-hydroxyapatite/ $\beta$-tricalcium phosphate ceramics scaffolds loaded with cationic liposomal ceftazidime: preparation, release characteristics in vitro and inhibition to Staphylococcus aureus biofilms. Drug Dev Ind Pharm. 2012;38(11): 1298-1304.

68. Ranjan A, Pothayee N, Seleem MN. Antibacterial efficacy of core-shell nanostructures encapsulating gentamicin against an in vivo intracellular Salmonella model. Int J Nanomed. 2009;4:289-297.

69. Ranjan A, Pothayee N, Vadala TP, et al. Efficacy of amphiphilic coreshell nanostructures encapsulating gentamicin in an in vitro salmonella and listeria intracellular infection model. Antimicrob Agents Chemother. 2010;54(8):3524-3526.

70. Hu D, Li H, Wang B, et al. Surface-adaptive gold nanoparticles with effective adherence and enhanced photothermal ablation of methicillinresistant Staphylococcus aureus biofilm. ACS Nano. 2017;11(9): 9330-9339.

71. Alves MM, Bouchami O, Tavares A, et al. New insights into antibiofilm effect of a nanosized $\mathrm{ZnO}$ coating against the pathogenic methicillin resistant Staphylococcus aureus. ACS Appl Mater Interfaces. 2017; 9(34):28157-28167.

72. Miller KP, Wang L, Chen YP, Pellechia PJ, Benicewicz BC, Decho AW. Engineering nanoparticles to silence bacterial communication. Front Microbiol. 2015;6:189.

73. Imbuluzqueta E. Drug delivery systems for potential treatment of intracellular bacterial infections. Front Biosci. 2010;15(1):397-417. 
74. Hua L, Hilliard JJ, Shi Y, et al. Assessment of an anti-alpha-toxin monoclonal antibody for prevention and treatment of Staphylococcus aureus-induced pneumonia. Antimicrob Agents Chemother. 2014; 58(2):1108-1117.

75. Chakraborty SP, Sahu SK, Mahapatra SK, et al. Nanoconjugated vancomycin: new opportunities for the development of anti-VRSA agents. Nanotechnology. 2010;21(10):105103.

76. Gupta PV, Nirwane AM, Belubbi T, Nagarsenker MS. Pulmonary delivery of synergistic combination of fluoroquinolone antibiotic complemented with proteolytic enzyme: a novel antimicrobial and antibiofilm strategy. Nanomedicine. 2017;13(7):2371-2384.

77. Hsu CY, Yang SC, Sung CT, Weng YH, Fang JY. Anti-MRSA malleable liposomes carrying chloramphenicol for ameliorating hair follicle targeting. Int J Nanomedicine. 2017;12:8227-8238.

78. Pornpattananangkul D, Zhang L, Olson S, et al. Bacterial toxintriggered drug release from gold nanoparticle-stabilized liposomes for the treatment of bacterial infection. J Am Chem Soc. 2011;133(11): 4132-4139.

79. Dees C, Schultz RD. The mechanism of enhanced intraphagocytic killing of bacteria by liposomes containing antibiotics. Vet Immunol Immunopathol. 1990;24(2):135-146.

80. Ahani E, Montazer M, Toliyat T, Mahmoudi Rad M, Harifi T. Preparation of nano cationic liposome as carrier membrane for polyhexamethylene biguanide chloride through various methods utilizing higher antibacterial activities with low cell toxicity. J Microencapsul. 2017; 34(2):121-131.

81. Baş AL, Simşek A, Erganiş O, Corlu M, Bas AL, Simsek A. Efficacies of liposome-encapsulated enrofloxacin against Staphylococcus aureus infection in Anatolian shepherd dog monocytes in vitro. Dtsch Tierarztl Wochenschr. 2005;112(6):219-223.

82. Baş LA, Simşek A, Corlu M, Yazar E, Elmas M, Değim ZG. Determination of intracellular concentrations of free and two types of liposomeencapsulated enrofloxacin in anatolian shepherd dog monocytes. $J$ Vet Med B Infect Dis Vet Public Health. 2002;49(6):289-293.

83. Zhao G, Hu C, Xue Y. In vitro evaluation of chitosan-coated liposome containing both coenzyme Q10 and alpha-lipoic acid: cytotoxicity, antioxidant activity, and antimicrobial activity. J Cosmet Dermatol. 2018; 17(2):258-262.

84. Nigatu AS, Ashar H, Sethuraman SN, et al. Elastin-like polypeptide incorporated thermally sensitive liposome improve antibiotic therapy against musculoskeletal bacterial pathogens. Int $J$ Hyperthermia. 2018;34(2):201-208.

85. Xie S, Yang F, Tao Y, et al. Enhanced intracellular delivery and antibacterial efficacy of enrofloxacin-loaded docosanoic acid solid lipid nanoparticles against intracellular Salmonella. Sci Rep. 2017; $7(1): 4110$

86. Uskoković V, Desai TA. Simultaneous bactericidal and osteogenic effect of nanoparticulate calcium phosphate powders loaded with clindamycin on osteoblasts infected with Staphylococcus aureus. Mater Sci Eng C Mater Biol Appl. 2014;37:210-222.

87. Chou J, Valenzuela S, Green DW, et al. Antibiotic delivery potential of nano- and micro-porous marine structure-derived $\beta$-tricalcium phosphate spheres for medical applications. Nanomedicine. 2014;9(8): $1131-1139$.

88. Akbari V, Abedi D, Pardakhty A, Sadeghi-Aliabadi H. Ciprofloxacin nano-niosomes for targeting intracellular infections: an in vitro evaluation. J Nanopart Res. 2013;15(4):1-14.

89. Geiser M. Update on macrophage clearance of inhaled micro- and nanoparticles. J Aerosol Med Pulm Drug Deliv. 2010;23(4):207-217.

90. Xie S, Tao Y, Pan Y, et al. Biodegradable nanoparticles for intracellular delivery of antimicrobial agents. J Control Release. 2014;187: 101-117.

91. Genestet C, Bernard-Barret F, Hodille E, et al. Antituberculous drugs modulate bacterial phagolysosome avoidance and autophagy in Mycobacterium tuberculosis-infected macrophages. Tuberculosis (Edinb). 2018;111:67-70.

92. Sahay G, Alakhova DY, Kabanov AV. Endocytosis of nanomedicines. J Control Release. 2010;145(3):182-195.
93. Sémiramoth N, di Meo C, Zouhiri F, et al. Self-assembled squalenoylated penicillin bioconjugates: an original approach for the treatment of intracellular infections. ACS Nano. 2012;6(5):3820-3831.

94. Allen TM, Austin GA, Chonn A, Lin L, Lee KC. Uptake of liposomes by cultured mouse bone marrow macrophages: influence of liposome composition and size. Biochim Biophys Acta. 1991;1061(1): 56-64.

95. Couvreur P, Vauthier C. Nanotechnology: intelligent design to treat complex disease. Pharm Res. 2006;23(7):1417-1450.

96. Beningo KA, Wang Y. Fc-receptor-mediated phagocytosis is regulated by mechanical properties of the target. J Cell Sci. 2012;115: 849-856.

97. Kalhapure RS, Sonawane SJ, Sikwal DR, et al. Solid lipid nanoparticles of clotrimazole silver complex: an efficient nano antibacterial against Staphylococcus aureus and MRSA. Colloids Surf B Biointerfaces. 2015;136:651-658.

98. Kalhapure RS, Mocktar C, Sikwal DR, et al. Ion pairing with linoleic acid simultaneously enhances encapsulation efficiency and antibacterial activity of vancomycin in solid lipid nanoparticles. Colloids Surf B Biointerfaces. 2014;117:303-311.

99. Li Y, Su T, Zhang Y, Huang X, Li J, Li C. Liposomal co-delivery of daptomycin and clarithromycin at an optimized ratio for treatment of methicillin-resistant Staphylococcus aureus infection. Drug Deliv. 2015;22(5):627-637.

100. Liu X, Li Z, Wang X, et al. Novel antimicrobial peptide-modified azithromycin-loaded liposomes against methicillin-resistant Staphylococcus aureus. Int J Nanomedicine. 2016;11:6781-6794.

101. Zhang D, Kong YY, Sun JH, et al. Co-delivery nanoparticles with characteristics of intracellular precision release drugs for overcoming multidrug resistance. Int J Nanomedicine. 2017;12:2081-2108.

102. Kalhapure RS, Jadhav M, Rambharose S, et al. pH-responsive chitosan nanoparticles from a novel twin-chain anionic amphiphile for controlled and targeted delivery of vancomycin. Colloids Surf $B$ Biointerfaces. 2017;158:650-657.

103. Kalhapure RS, Sikwal DR, Rambharose S, et al. Enhancing targeted antibiotic therapy via $\mathrm{pH}$ responsive solid lipid nanoparticles from an acid cleavable lipid. Nanomedicine. 2017;13(6):2067-2077.

104. Aurore V, Caldana F, Blanchard M, et al. Silver-nanoparticles increase bactericidal activity and radical oxygen responses against bacterial pathogens in human osteoclasts. Nanomedicine. 2018;14(2): 601-607.

105. Richter K, Thomas N, Zhang G, et al. Deferiprone and galliumprotoporphyrin have the capacity to potentiate the activity of antibiotics in Staphylococcus aureus small colony variants. Front Cell Infect Microbiol. 2017;7:280.

106. Wang XF, Zhang SL, Zhu LY, et al. Enhancement of antibacterial activity of tilmicosin against Staphylococcus aureus by solid lipid nanoparticles in vitro and in vivo. Vet J. 2012;191(1):115-120.

107. Xie Y, Liu Y, Yang J. Gold nanoclusters for targeting MRSA in vivo. Angew Chem Int Ed Eng. 2018;57(15):3958-3962.

108. Jadhav M, Kalhapure RS, Rambharose S, et al. Novel lipids with three $\mathrm{C}_{18}$-fatty acid chains and an amino acid head group for $\mathrm{pH}$ responsive and sustained antibiotic delivery. Chem Phys Lipids. 2018;212:12-25.

109. Guo J, Zhou H, Wang J, et al. Nano vanadium dioxide films deposited on biomedical titanium: a novel approach for simultaneously enhanced osteogenic and antibacterial effects. Artif Cells Nanomed Biotechnol. 2018;21:1-17.

110. Zhao Z, Yan R, Yi X, et al. Bacteria-activated theranostic nanoprobes against methicillin-resistant Staphylococcus aureus infection. ACS Nano. 2017;11(5):4428-4438.

111. Nimal TR, Baranwal G, Bavya MC, Biswas R, Jayakumar R. Antistaphylococcal activity of injectable nano tigecycline/chitosan-PRP composite hydrogel using Drosophila melanogaster model for infectious wounds. ACS Appl Mater Interfaces. 2016;8(34):22074-22083.

112. Deng Y, Kizer M, Rada M, et al. Intracellular delivery of nanomaterials via an inertial microfluidic cell hydroporator. Nano Lett. 2018;18(4):2705-2710. 
113. Kaprelyants AS, Gottschal JC, Kell DB. Dormancy in non-sporulating bacteria. FEMS Microbiol Rev. 1993;10(3-4):271-286.

114. Anisimova YV, Gelperina SI, Peloquin CA, Heifets LB. Nanoparticles as antituberculosis drugs carriers: effect on activity against mycobacterium tuberculosis in human monocyte-derived macrophages. J Nanopart Res. 2000;2(2):165-171.

115. Lin PL, Flynn JL. Understanding latent tuberculosis: a moving target. J Immunol. 2010;185(1):15-22.

116. Ma T, Shang BC, Tang H, et al. Nano-hydroxyapatite/chitosan/konjac glucomannan scaffolds loaded with cationic liposomal vancomycin: preparation, in vitro release and activity against Staphylococcus aureus biofilms. J Biomater Sci Polym Ed. 2011;22(12):1669-1681.

117. Pei Y, Mohamed MF, Seleem MN, Yeo Y. Particle engineering for intracellular delivery of vancomycin to methicillin-resistant Staphylococcus aureus (MRSA)-infected macrophages. J Control Release. 2017;267:133-143.

118. Mao C, Xie X, Liu X, et al. The controlled drug release by $\mathrm{pH}$-sensitive molecularly imprinted nanospheres for enhanced antibacterial activity. Mater Sci Eng C Mater Biol Appl. 2017;77:84-91.

119. Xue Y, Xia X, Yu B, et al. A green and facile method for the preparation of a pH-responsive alginate nanogel for subcellular delivery of doxorubicin. RSC Adv. 2015;5(90):73416-73423.
120. Murakami M, Cabral H, Matsumoto $Y$, et al. Improving drug potency and efficacy by nanocarrier-mediated subcellular targeting. Sci Transl Med. 2011;3(64):ra2.

121. Ashby M, Petkova A, Hilpert K. Cationic antimicrobial peptides as potential new therapeutic agents in neonates and children: a review. Curr Opin Infect Dis. 2014;27(3):258-267.

122. Lopez Cascales JJ, Garro A, Porasso RD, Enriz RD. The dynamic action mechanism of small cationic antimicrobial peptides. Phys Chem Chem Phys. 2014;16(39):21694-21705.

123. George S, Kishen A. Augmenting the antibiofilm efficacy of advanced noninvasive light activated disinfection with emulsified oxidizer and oxygen carrier. J Endod. 2008;34(9):1119-1123.

124. George S, Kishen A. Photophysical, photochemical, and photobiological characterization of methylene blue formulations for light-activated root canal disinfection. J Biomed Opt. 2007;12(3):034029.

125. Shrestha A, Cordova M, Kishen A. Photoactivated polycationic bioactive chitosan nanoparticles inactivate bacterial endotoxins. $J$ Endod. 2015;41(5):686-691.

126. Zhang Y, Zhang J, Chen W, et al. Erythrocyte membrane-coated nanogel for combinatorial antivirulence and responsive antimicrobial delivery against Staphylococcus aureus infection. J Control Release. 2017;263:185-191.
International Journal of Nanomedicine

\section{Publish your work in this journal}

The International Journal of Nanomedicine is an international, peerreviewed journal focusing on the application of nanotechnology in diagnostics, therapeutics, and drug delivery systems throughout the biomedical field. This journal is indexed on PubMed Central,

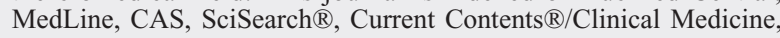

\section{Dovepress}

Journal Citation Reports/Science Edition, EMBase, Scopus and the Elsevier Bibliographic databases. The manuscript management system is completely online and includes a very quick and fair peer-review system, which is all easy to use. Visit http://www.dovepress.com/ testimonials.php to read real quotes from published authors. 